\title{
Radiation-induced neuropathic pain successfully treated with systemic lidocaine administration
}

This article was published in the following Dove Press journal: Journal of Pain Research

\author{
A Ram Doo' \\ Yu Seob Shin ${ }^{2}$ \\ Seonwoo Yoo' \\ Jong Kwan Park² \\ 'Department of Anesthesiology \\ and Pain Medicine, ${ }^{2}$ Department of \\ Urology, Chonbuk National University \\ and Research Institute of Clinical \\ Medicine of Chonbuk National \\ University-Biomedical Research \\ Institute and Clinical Trial Center of \\ Medical Device of Chonbuk National \\ University, Jeonju, South Korea
}

\begin{abstract}
Radiation-induced neuropathic pain is a rare but devastating complication following cancer treatment. It is often progressive, refractory to conservative treatment, and sometimes irreversible. The exact mechanism of radiation-induced neuropathic pain is unknown, but it is associated with perineural fibrosis, atrophy, and ischemia. Systemic administration of local anesthetics is known to be effective for various acute and chronic painful diseases, such as neuropathic pain, as well as inflammatory and nociceptive pains. We report a patient with generalized radiation-induced neuropathic pain successfully treated with systemic lidocaine administration. Keywords: cancer, complication, lidocaine, pain, neuropathy
\end{abstract}

\section{Introduction}

Radiation treatment is a mainstay of cancer therapy. Although radiotherapy has improved the survival of cancer patients, it unfortunately can harm exposed areas. Ionizing radiation not only breaks down cancer cells but may also affect adjacent noncancerous cells by releasing various cytokines and inflammatory mediators from killed cancer cells. The inflammatory reaction can cause fibrosis, atrophy, and ulceration of the tissues, including vessels and nerves, and consequently nerve damage may result. ${ }^{1}$ Although radiation-induced neuropathy is known to be caused by this complex interaction, the exact mechanism of this painful disease is still unclear. Methodologically sound trials for radiation-induced neuropathy are scarce, and few case reports have been published. Radiation-induced neuropathic pain is often progressive, unresponsive to conservative treatment, and sometimes irreversible. We report on a case of intractable radiationinduced neuropathic pain successfully treated with systemic lidocaine administration.

\section{Case report}

Written Informed consent for publication was obtained from the patient. A 60-year-old male patient visited our pain clinic, referred from a tertiary hospital, with a complaint of chronic burning, itching, aching pain, and restlessness of the whole body, mainly in both arms and legs, and concomitant myalgia and chills during pain attacks (numeric rating of 9 on a scale of 10) for about 6 years. The patient had received a liver transplant because of hepatocellular carcinoma 10 years before, but just a few years later, metastatic cancers of his lung and adrenal gland were detected in turn, and right-upper-lobe wedge resection of the lung and an adrenalectomy were performed uneventfully. Then he had to get radiation treatment for metastatic cancer of the left iliac bone. Radiation treatment was performed with a total dose of 50 Gy in ten fractions using external-
Correspondence: Jong Kwan Park Department of Urology, Medical School, Chonbuk National University, 20 Geonji-ro, Deokjin-gu, Jeonju, Jeollabuk-do 54907, South Korea

Tel +82632501510

Fax +82 $63250 I 564$

Email rain@chonbuk.ac.kr 
beam radiotherapy for 2 weeks. A month after completing the radiation treatment, he had experienced both pelvic and perineal pain radiating to the groin and penis, with a feeling of itching and aching. The pain had progressively spread into the whole body for 2 years, and the intensity of the pain worsened continuously.

Even though he had received ganglion impar neurolysis and superior hypogastric plexus neurolysis several times and had been taking many useful medications, including high-dose opioids, his pain was refractory to the treatments. He said that neurolytic treatments had a limited effect for only a day. On the visit to our clinic, he was taking pregabalin $450 \mathrm{mg} /$ day (Pfizer Inc., New York, NY, USA), milnacipran 100 mg/day (Bukwang Pharm. co., Seoul, Korea), high-dose transdermal fentanyl $350 \mu \mathrm{g}$ /hour (LTS Lohmann Therapie-Systeme AG, Andernach, Germany), and other strong opioids, such as sublingual fentanyl (Menarini Korea Ltd., Seoul, Korea), tramadol-paracetamol (Janssen Korea Ltd., Seoul, Korea), and oxycodone (Mundipharma Korea Ltd., Seoul, Korea), for the breakthrough intractable pain. He also complained of cutaneous allergic reactions to the transdermal fentanyl patch on multiple sites on his body. Physical examination found no tenderness on pelvic muscles, including piriformis, iliopsoas, and levator ani muscles. Whole-spine magnetic resonance imaging scanned at the time of the visit showed no specific findings, except a signal change of a previously metastatic lesion of the left iliac bone and a degenerative change in cervical, thoracic, and lumbar spine, such as multilevel disc bulging. The patient had no diabetes mellitus, cardiovascular disease, or rheumatologic disease.

Radiation-induced generalized neuropathic pain was suspected, and systemic intravenous nonopiate infusion was considered for relieving the patient's symptoms. Because his pain was present throughout his whole body, not localized, certain interventional procedures, such as a nerve block or neurolysis, were thought not to be suitable. Moreover, the sympathetic ganglion neurolysis that he had already received several times had not produced meaningful improvement. Lidocaine $5 \mathrm{mg} / \mathrm{kg}$ was intravenously administered for 30 minutes, electrocardiography, pulse oximetry, and blood pressure were monitored, and signs of possible systemic toxicity of local anesthetics were observed by an anesthesiologist. There was no sign of side effects during or after lidocaine infusion. Repeated lidocaine-infusion therapy was planned every 14 days. On the second visit, the patient reported gradual pain relief, with $30 \%$ reduction in pain intensity, and his pain score had decreased from 9 to 7 on a 10-point scale. Moreover, the patient was able to reduce the use of transdermal fentanyl from $350 \mu \mathrm{g} /$ hour to $200 \mu \mathrm{g} /$ hour. The second therapy was performed in the same way as the first.
After 14 days, the patient reported much more substantial pain relief, with a pain score of 3 and = a much smaller dose $(150$ $\mu \mathrm{g} /$ hour) of transdermal fentanyl, but he still complained of residual, vague, and fluctuating pain of the whole body, so a third therapy was performed. After 14 days, the patient reported that his pain had markedly decreased to a pain score of 0 and remained stable, a mild heating sensation only remained, and 87 $\mu \mathrm{g} /$ hour transdermal fentanyl was being delivered. He remained stable and was satisfied with the treatment result.

\section{Discussion}

Pain in cancer survivors is a growing concern as survival rates increase. In fact, persistent and chronic pain, even after a cancer cure, is the unsolved problem, which is a great burden to patients psychologically as well as physically, and is well known to influence quality of life negatively and increase health care costs. ${ }^{2,3}$ Harrison et al revealed that $89 \%$ of patients with persistent pain after tongue cancer treatment with radiotherapy suffered from moderate-severe distress. ${ }^{4}$ The causes of pain after cancer treatment are many. Pain may develop after chemotherapy (chemotherapy-induced peripheral neuropathy), radiotherapy, surgery (persistent postsurgical pain), hormone therapy, or stem-cell transplantation, with an overall prevalence of approximately $30 \% .^{5-8}$

Radiation treatment is one of the mainstays of cancer therapy. Mechanisms of ionizing radiation for killing cancer cells are direct and indirect DNA damage, associated with reactive oxygen species production and inhibited DNA repair. Radiation exposure can induce breakdown of cancer cells, causing the release of various cytokines and inflammatory mediators, and can also affect noncancerous cells. This inflammatory reaction causes fibrosis, atrophy, and ulceration of the related tissue, including vessels and nerves. Perineural fibrosis and ischemia, subsequently developing myelin destruction and axonal injury, are attributed to the main mechanism of radiation-induced neuropathic pain, such as radiation-induced brachial plexopathy after radiotherapy for breast carcinoma. ${ }^{1,9}$ In addition, radiation treatment may produce various types of postradiation chronic pain syndromes, including peripheral nerve entrapment, radiculopathy, myelopathy, noncardiac chest pain, pelvic pain, osteonecrosis, and other soft-tissue damage at the sites exposed. ${ }^{1,3,9-11}$ Above all, pelvic pain after radiotherapy can arise from pelvic insufficiency fracture, enteritis, abdominal visceral pain, or neural injury. ${ }^{11}$ Andreyev et al defined pelvic radiation disease as a transient or longerterm problem, affecting the bowels, urinary tract, sex organs, bones, or skin after radiotherapy to tumors of pelvic origin. ${ }^{12}$ However, in our case, there was no evidence of pelvic radia- 
tion disease, nor had the patient experienced any dysfunction in the gastrointestinal or genitourinary systems following radiation treatment for pelvic-bone metastasis.

Radiation-induced pudendal neuropathy might have been the primary cause of the patient's pain in our case, though it is a very rare complication secondary to radiotherapy, because he first experienced pelvic and perineal pain radiating to the penis and groin 1 month after pelvic radiation treatment, which corresponds with clinical features of pudendal neuropathy. If diagnostic and therapeutic pudendal nerve block had been performed at that time, it would have been of great value for the diagnosis. However, only ganglion impar neurolysis and superior hypogastric plexus neurolysis were performed (several times), and the treatments failed to relieve his pain. Elahi et al reported that pudendal entrapment neuropathy following pelvic radiation therapy may be successfully treated with spinal cord stimulation if other conservative treatment modalities fail, ${ }^{13}$ but in this case we chose systemic drug infusion as the primary treatment, because his pain was spread throughout his whole body, which may have meant central sensitization, instead of being focused on localized areas, for which certain interventional treatments are available.

Although it is one of the most extensively investigated and used local anesthetic drugs, systemically administered lidocaine can also act as an analgesic by blocking peripheral and central voltage-gated sodium channels, and increasing spinal inhibitory glycinergic neurotransmission mediated by $N$-methyl-D-aspartate receptors. Especially in neuropathic pain, lidocaine acts in abnormally overexpressed voltagegated sodium channels on the cell membranes of injured peripheral nerves producing ectopic discharge, dorsal root ganglia, and adjacent neurons. ${ }^{14,15}$ The fact that systemic lidocaine-infusion treatments are effective for various acute and chronic painful diseases, such as neuropathic pain, as well as inflammatory and nociceptive pains, is not surprising. ${ }^{16-18}$ A systemic review and meta-analysis concluded that the effects of systemically administered local anesthetics including intravenous lidocaine were superior to a placebo and equal to other pain modulators, such as gabapentin, amitriptyline, or morphine, for relieving neuropathic pain. ${ }^{16}$ Nevertheless, to the best of our knowledge, this is the first case report to suggest the efficacy of systemic lidocaine treatment for radiation-induced neuropathic pain. Radiation-induced neuropathic pain is often unresponsive to conservative treatment and sometimes irreversible. We think that systemic lidocaine is worth applying in a patient with intractable radiationinduced neuropathic pain, even if it is a centrally sensitized state, as a rescue-treatment modality.
Meanwhile, it is notable that systemic lidocaine treatment can help to reduce opioid consumption. In fact, increasing dosages of opioids are routinely chosen to relieve chronic intractable pain by many physicians, because opioids reduce pain immediately and strongly for most patients without a ceiling effect. Moreover, opioids have been accepted as safe analgesic medication for cancer patients, with little possibility of aberrant drug-related behaviors, such as addiction. However, for patients with noncancer pain, including cancer survivors, long-term opioid medications may have harmful effects, such as opioid-use disorder, overdosing, and life-threatening adverse effects. Higher opioid doses may contribute to an increased risk of opioid-related death. ${ }^{19,20}$ As our findings demonstrate, systemic lidocaine treatment can help to reduce opioid consumption and relieve pain in patients with intractable radiation-induced neuropathic pain.

Pain in cancer survivors should be evaluated precisely and treated by multimodal methods. First, an exact medical history, including prior cancer treatment and complicated problems and other physical or psychological disease, should be taken. Various imaging modalities, neurologic tests, or diagnostic block methods if possible may help diagnose the cause of pain. Additionally, other potential causes of pain should be considered, not only cancer-treatment-related pain syndromes but also other specific painful diseases, such as musculoskeletal disorders, neuropathies, or other medical diseases, whenever there are inexplicable changes in the nature, location, or intensity of pain. Multimodal approaches, including pharmacological, psychosocial, and interventional approaches, can be used for symptom improvement and functional recovery. Our experience with this patient suggests that systemic drug-infusion therapy may be a valuable part of the treatment strategy for radiation-induced neuropathic pain refractory to conventional pharmacological treatment.

\section{Acknowledgment}

This study was supported by funds from the Biomedical Research Institute of Chonbuk National University Hospital, Jeonju, South Korea.

\section{Author contributions}

All authors contributed toward data analysis, drafting, and critically revising the paper, gave final approval of the version to be published, and agree to be accountable for all aspects of the work.

\section{Disclosure}

The authors report no conflicts of interest in this work. 


\section{References}

1. Delanian S, Lefaix JL, Pradat PF. Radiation-induced neuropathy in cancer survivors. Radiother Oncol. 2012;105(3):273-282.

2. Green CR, Hart-Johnson T, Loeffler DR. Cancer-related chronic pain: examining quality of life in diverse cancer survivors. Cancer. 2011;117(9): 1994-2003.

3. Pachman DR, Barton DL, Swetz KM, Loprinzi CL. Troublesome symptoms in cancer survivors: fatigue, insomnia, neuropathy, and pain. J Clin Oncol. 2012;30(3):3687-3696.

4. Harrison LB, Zelefsky MJ, Pfister DG, et al. Detailed quality of life assessment in patients treated with primary radiotherapy for squamous cell cancer of the base of the tongue. Head Neck. 1997;19(3): 169-175.

5. Glare PA, Davies PS, Finlay E, et al. Pain in cancer survivors. J Clin Oncol. 2014;32(16):1739-1747.

6. van den Beuken-van Everdingen MH, de Rijke JM, Kessels AG, Schouten HC, van Kleef M, Patijn J. Prevalence of pain in patients with cancer: a systematic review of the past 40 years. Ann Oncol. 2007;18(9): 1437-1449.

7. Brown MR, Ramirez JD, Farquhar-Smith P. Pain in cancer survivors. Br J Pain. 2014;8(4):139-153.

8. Burton AW, Fanciullo GJ, Beasley RD, Fisch MJ. Chronic pain in the cancer survivor: a new frontier. Pain Med. 2007;8(2):189-198.

9. Fathers E, Thrush D, Huson SM, Norman A. Radiation-induced brachial plexopathy in women treated for carcinoma of the breast. Clin Rehabil. 2002;16(2):160-165.

10. Jeon SY, Moon HS, Han YJ, Sung CH. Post-radiation piriformis syndrome in a cervical cancer patient: a case report. Korean J Pain. 2010;23(1):88-91.
11. Ogino I, Okamoto N, Ono Y, Kitamura T, Nakayama H. Pelvic insufficiency fractures in postmenopausal woman with advanced cervical cancer treated by radiotherapy. Radiother Oncol. 2003;68(1):61-67.

12. Andreyev HJ, Wotherspoon A, Denham JW, Hauer-Jensen M. Defining pelvic-radiation disease for the survivorship era. Lancet Oncol. 2010;11(4):310-312.

13. Elahi F, Callahan D, Greenlee J, Dann TL. Pudendal entrapment neuropathy: a rare complication of pelvic radiation therapy. Pain Physician. 2013;16(6):E793-E797.

14. Devor M. Neuropathic pain and injured nerve: peripheral mechanisms. Br Med Bull. 1991;47(3):619-630.

15. Matzner O, Devor M. Hyperexcitability at sites of nerve injury depends on voltage-sensitive Na+ channels. JNeurophysiol. 1994;72(1):349-359.

16. Tremont-Lukats IW, Challapalli V, McNicol ED, Lau J, Carr DB. Systemic administration of local anesthetics to relieve neuropathic pain: a systematic review and meta-analysis. Anesth Analg. 2005;101(6):1738-1749.

17. Kosharskyy B, Almonte W, Shaparin N, Pappagallo M, Smith H. Intravenous infusions in chronic pain management. Pain Physician. 2013;16(3):231-249.

18. Challapalli V, Tremont-Lukats IW, McNicol ED, Lau J, Carr DB. Systemic administration of local anesthetic agents to relieve neuropathic pain. Cochrane Database Syst Rev. 2005;(4):CD003345.

19. Bohnert AS, Valenstein M, Bair MJ, et al. Association between opioid prescribing patterns and opioid overdose-related deaths. JAMA. 2011;305(15):1315-1321.

20. Gomes T, Mamdani MM, Dhalla IA, Paterson JM, Juurlink DN. Opioid dose and drug-related mortality in patients with nonmalignant pain. Arch Intern Med. 2011;171(7):686-691.
Journal of Pain Research

\section{Publish your work in this journal}

The Journal of Pain Research is an international, peer reviewed, open access, online journal that welcomes laboratory and clinical findings in the fields of pain research and the prevention and management of pain. Original research, reviews, symposium reports, hypothesis formation and commentaries are all considered for publication.

\section{Dovepress}

The manuscript management system is completely online and includes a very quick and fair peer-review system, which is all easy to use. Visit http://www.dovepress.com/testimonials.php to read real quotes from published authors. 